\title{
Risk factors for postoperative mortality in congenital diaphragmatic hernia: a single-centre observational study
}

\author{
Darya Kadir $^{1,2} \cdot$ Helene Engstrand Lilja ${ }^{1,2}$ (1)
}

Accepted: 5 December 2016/Published online: 16 December 2016

(C) The Author(s) 2016. This article is published with open access at Springerlink.com

\begin{abstract}
Background The management of congenital diaphragmatic hernia $(\mathrm{CDH})$ is a major challenge. The mortality is dependent on associated malformations, the severity of pulmonary hypoplasia, pulmonary hypertension and iatrogenic lung injury associated with aggressive mechanical ventilation. The aims of the study were to investigate the mortality over time in a single paediatric surgical centre, to compare the results with recent reports and to define the risk factors for mortality.

Methods The medical records of infants with CDH from two time periods: 1995-2005 and 2006-2016 were reviewed. Cox regression was used for statistical analysis. Results The study included 113 infants. The mortality rate was significantly decreased in the later time period, compared to the earlier, 4.4 and $17.9 \%$, respectively. At the early time period five patients $(7.5 \%)$ were treated with ECMO and in the later time period ECMO was used in three patients $(6.5 \%)$. The mortality in ECMO-treated patients was $50 \%$ in both time periods. Prenatal diagnosis, intrathoracic liver, low Apgar score and low birth weight were defined as independent risk factors for mortality. Conclusion Despite no significant differences in the incidence of independent risk factors and the use of
\end{abstract}

Helene Engstrand Lilja

helene.lilja@kbh.uu.se

1 Department of Women's and Children's Health, Section of Pediatric Surgery, Uppsala University, 75185 Uppsala, Sweden

2 Department of Pediatric Surgery, University Children's Hospital, Uppsala, Sweden
ECMO between the two time periods, mortality decreased over time. The mortality was lower than previously reported. The results indicate that there are many important factors involved in a successful outcome after $\mathrm{CDH}$ repair. Large multicentre studies are necessary to define those critical factors and to determine optimal treatment strategies.

Keywords Congenital diaphragmatic hernia . Postoperative outcome $\cdot$ Risk factors

\section{Introduction}

The management of congenital diaphragmatic hernia $(\mathrm{CDH})$ is a major challenge in paediatric surgery. The incidence of $\mathrm{CDH}$ is between 1 in 2500 and 5000 live births [1-3]. A mortality rate of $10-30 \%$ has been reported but is still higher in patients with severe pulmonary hypoplasia and pulmonary hypertension [4-8]. Mortality in $\mathrm{CDH}$ patients treated with extracorporeal membrane oxygenation (ECMO) was approximately 50\% in a recent report from ELSO (Extracorporeal Life Support Organisation) [9]. Prenatal diagnosis, LHR (lung-tohead-ratio) $n<1$, intrathoracic liver, right-sided $\mathrm{CDH}$, associated malformations, a large diaphragmatic defect, low 5-min Apgar score and prematurity are other factors that have been associated with high mortality $[2,3,8,10-16]$. Also the timing of surgery might influence the mortality rate in high-risk $\mathrm{CDH}$ and the practice of clinical stability before surgery is widely advocated $[10,17,18]$. The aims of the study were to investigate the mortality over time in a single paediatric surgical centre, to compare the results with recent reports and to define the risk factors for mortality. 
Table 1 Patient characteristics in the two different time periods

\begin{tabular}{lccc}
\hline Patient characteristics & $1995-2005(n=67)$ & $2006-2016(n=46)$ & $p$ value \\
\hline Boys & $34(50.8 \%)$ & $26(56.5 \%)$ & 0.570 \\
Girls & $33(49.2 \%)$ & $20(43.5 \%)$ & \\
Prenatal diagnosis & $19(28.4 \%)$ & $16(34.8 \%)$ & 0.536 \\
Intrathoracic liver & $15(22.4 \%)$ & $6(13 \%)$ & 0.231 \\
Median gestational age weeks (range) & $38(24-42)$ & $38(30-42)$ & 0.238 \\
Median birth weight grams (range) & $3192(706-4341)$ & $3215(1500-4774)$ & 0.147 \\
Major cardiac defects & $9(13.4 \%)$ & $12(26.1 \%)$ & 0.138 \\
Chromosomal abnormalities & $2(3 \%)$ & $1(2.2 \%)$ & 1.000 \\
Other malformations & $10(14.9 \%)$ & $5(10.9 \%)$ & 0.586 \\
Large defect size & $26(40.6 \%)$ & $14(31.8 \%)$ & 0.284 \\
Right sided & $13(19.4 \%)$ & $6(13.0 \%)$ & 0.449 \\
Median age at surgery days (range) & $2(1-3638)$ & $3(1-1159)$ & 0.937 \\
ECMO & $5(7.5 \%)$ & $3(6.5 \%)$ & 1.000 \\
Mortality rate & $12(17.9 \%)$ & $2(4.4 \%)$ & 0.041 \\
\hline
\end{tabular}

\section{Patients and methods}

This is a retrospective observational study of all the infants with repaired CDH between January 1995 and January 2016 at the University Children's Hospital, Uppsala, Sweden. Neonates primarily managed in our centre who were sent for ECMO to other paediatric surgical centres were also included. Patients with primary repair in other centres who later had a repair of recurrent $\mathrm{CDH}$ in our centre and patients not surviving until surgery were excluded. Patients with diaphragmatic eventration were excluded. The use of patient data in this study was approved by the Regional Committee on Medical Research Ethics (Dnr 2016/140). Data extracted from the medical records were prenatal diagnosis, LHR, liver in thorax, gender, gestational age and birth weight, Apgar score, treatment with ECMO, age at surgery (days), side of the defect, associated malformations, the size of the defect as determined by the surgeon at the time of surgery and if a patch was used. If the patient died, the age at death was registered. The study period was 900 days after surgery or until death. A major cardiac anomaly was defined according to Spitz (congenital heart disease that required medical or surgical treatment) [19].

\section{Statistical analysis}

Descriptive statistics are presented as median and range for continuous variables and as absolute and relative frequencies for categorical variables. Survival is presented as Kaplan-Meier curves. All patients that underwent CDH repair were included in the Kaplan-Meier estimate, regardless of the length of follow-up time. Possible independent risk factors for mortality were analysed in three steps. In the first step, selected independent factors had been evaluated using univariate Cox proportional hazards model presented as Hazard ratio (HR) with $95 \%$ confidence interval (CI). In the second step, variables with a $p$ value $<0.05$ in the univariate analysis were entered into a multivariate analysis. In the third step, the model was subject to a backward stepwise procedure where the best model was determined as the model with the smallest Akaike information criteria (AIC) value. Estimates where $p<0.05$ were considered significant, but since no adjustment for multiplicity has been performed the overall type I error rate may exceed 5\%. Thus, the $p$ values should be interpreted in an exploratory manner rather than as confirmatory. Statistical analyses were performed using $\mathrm{R}$ version 3.2.2, Copyright (C) 2015 The R Foundation for Statistical Computing.

\section{Results}

A total of 113 patients were included, 67 in the early time period (1995-2005) and 46 in the later time period (2006-2016) (Table 1). The distribution of males and females was similar in both time periods. Median gestational age was 38 weeks in both time periods and birth weight was $3192 \mathrm{~g}$ in the early and $3215 \mathrm{~g}$ in the later time period. Median age at surgery was 2 days in the early and 3 days in the later time period. The incidence of major cardiac anomaly was $13.4 \%$ in the early and $26.1 \%$ in the later time period and the incidence of chromosomal abnormalities was $3 \%$ in the early and $2.2 \%$ in the later time period. The frequencies of other malformations such as esophageal atresia, gastroschisis, bladder exstrophy, omphalocele, myelomeningocele, Pentalogy of Cantrell, Fryns- and Pierre Robin syndrome and renal agenesis were 
Table 2 Characteristics of neonates who died prior to surgery or were not candidates for surgical repair

\begin{tabular}{|c|c|c|c|c|c|c|c|c|c|c|}
\hline Patient & 1 & 2 & 3 & 4 & 5 & 6 & 7 & 8 & 9 & 10 \\
\hline Gender & M & M & $\mathrm{F}$ & $\mathrm{F}$ & M & $\mathrm{F}$ & M & $\mathrm{F}$ & M & M \\
\hline Prenatal diagnosis & Yes & Yes & No & No & Yes & Yes & No & No & Yes & Yes \\
\hline $\begin{array}{l}\text { Gestational age } \\
\text { (weeks) }\end{array}$ & 37 & 33 & 35 & 40 & 38 & 35 & 37 & 36 & 33 & 25 \\
\hline Birth weight (g) & 2350 & 1950 & 1790 & 1981 & 3420 & 1460 & 3000 & 2200 & 1770 & 683 \\
\hline Major cardiac defect & Yes & No & No & Yes & Yes & No & No & Yes & No & Yes \\
\hline $\begin{array}{l}\text { Chromosomal } \\
\text { abnormalities }\end{array}$ & No & No & Yes & $\begin{array}{c}\text { Trisomy } \\
18\end{array}$ & No & No & No & $\begin{array}{c}\text { Trisomy } \\
18\end{array}$ & No & No \\
\hline Other malformations & $\begin{array}{l}\text { Fryns } \\
\text { syndrome }\end{array}$ & Multiple $^{\mathrm{a}}$ & $\begin{array}{l}\text { Cornelia de } \\
\text { Lange }\end{array}$ & No & No & $\begin{array}{l}\text { Fryns } \\
\text { syndrome }\end{array}$ & No & No & Multiple $^{\mathrm{b}}$ & No \\
\hline Side of the defect & Left & Left & Right & Left & Left & Left & Right & Left & Bilat & Left \\
\hline Age at death (days) & $<1$ & $<1$ & $<1$ & $<1$ & $<1$ & $<1$ & $<1$ & 9 & $<1$ & $<1$ \\
\hline
\end{tabular}

${ }^{a}$ Esophageal atresia, myelomeningocele, renal agenesis

b Omphalocele, myelomeningocele, bladder exstrophy

$14.9 \%$ in the early and $10.9 \%$ in the later period. Prenatal diagnosis was found in $28.4 \%$ of the patients in the early and $34.8 \%$ in the later time period and the incidence of intrathoracic liver was $22.4 \%$ in the early and $13 \%$ in the later time period.

The LHR measurements started in the period between 2006 and 2016. Data on LHR were missing in 6 out of 16 patients with prenatal diagnosis, and were too few to be included in the analysis. At the early time period $40.6 \%$ of the patients had a large diaphragmatic defect compared to $31.8 \%$ in the later time period (Table 1). Five patients $(7.5 \%)$ were treated with ECMO in the early and three patients $(6.5 \%)$ in the later time period. The mortality in those patients was $50 \%$. The mortality rate of $4.4 \%$ was significantly lower in the period between 2006 and 2016 compared to $17.9 \%$ in the period from 1995 to 2005 as demonstrated in Table 1. During the whole study period from 1995 to 2016, the overall mortality was $12.3 \%$ and if neonates who died before surgery were included, the mortality rate was $19.5 \%$. In Table 2 , neonates who died prior to surgery or were not candidates for surgical repair are shown. Patient number 1-8 were born during the early time period and number 9 and 10 during the later time period. In patient number 4 and 8 , withdrawal of care was done due to trisomy 18 .

Patients died earlier after surgery in the early time period (Fig. 1). The survival in patients with a small defect was $100 \%$ compared to $72 \%$ in patients with a large diaphragmatic defect as demonstrated in Fig. 2. Table 3 demonstrates the potential risk factors included in the univariate Cox proportional hazards model. The risk to die was 6.89 times higher in patients with a large diaphragmatic defect. Patients with an intrathoracic liver had 6.37 times higher risk, infants with a prenatal diagnosis 4.32 and ECMO-treated patients had 6.61 times higher risk to die than patients without those risk factors. Multivariate analysis confirmed a significant association with mortality independent of the other variables for prenatal diagnosis, intrathoracic liver, low Apgar score and low birth weight as demonstrated in Table 4. For every $100 \mathrm{~g}$ increase in birth weight, the risk to die was reduced by $7 \%$ and for every increase in Apgar score the risk to die was reduced by $34 \%$. Prenatal diagnosis and intrathoracic liver increased the risk to die with 4.55 and 4.0 times, respectively.

\section{Discussion}

Comparing mortality between different reports is confusing as mortality rates are reported for heterogenous populations with $\mathrm{CDH}$ from centres with highly varied treatment strategies and volumes of patients. In the study populations, there is a great variation in the proportion of prenatally diagnosed $\mathrm{CDH}$, follow-up time, whether they include only live-born neonates, if they include neonates that die before surgery or only patients that undergo surgery. We have performed this study to be able to compare our results with international reports. During the study period of two decades, there have been changes in both surgical and medical practices. The repair of $\mathrm{CDH}$ has changed from a surgical emergency in the beginning of the study period to a planned surgery after stabilization. The first neonate with $\mathrm{CDH}$ in our unit that received ECMO 
Fig. 1 Kaplan-Meier estimates of the cumulative risk of survival up to 900 days in the two different time periods

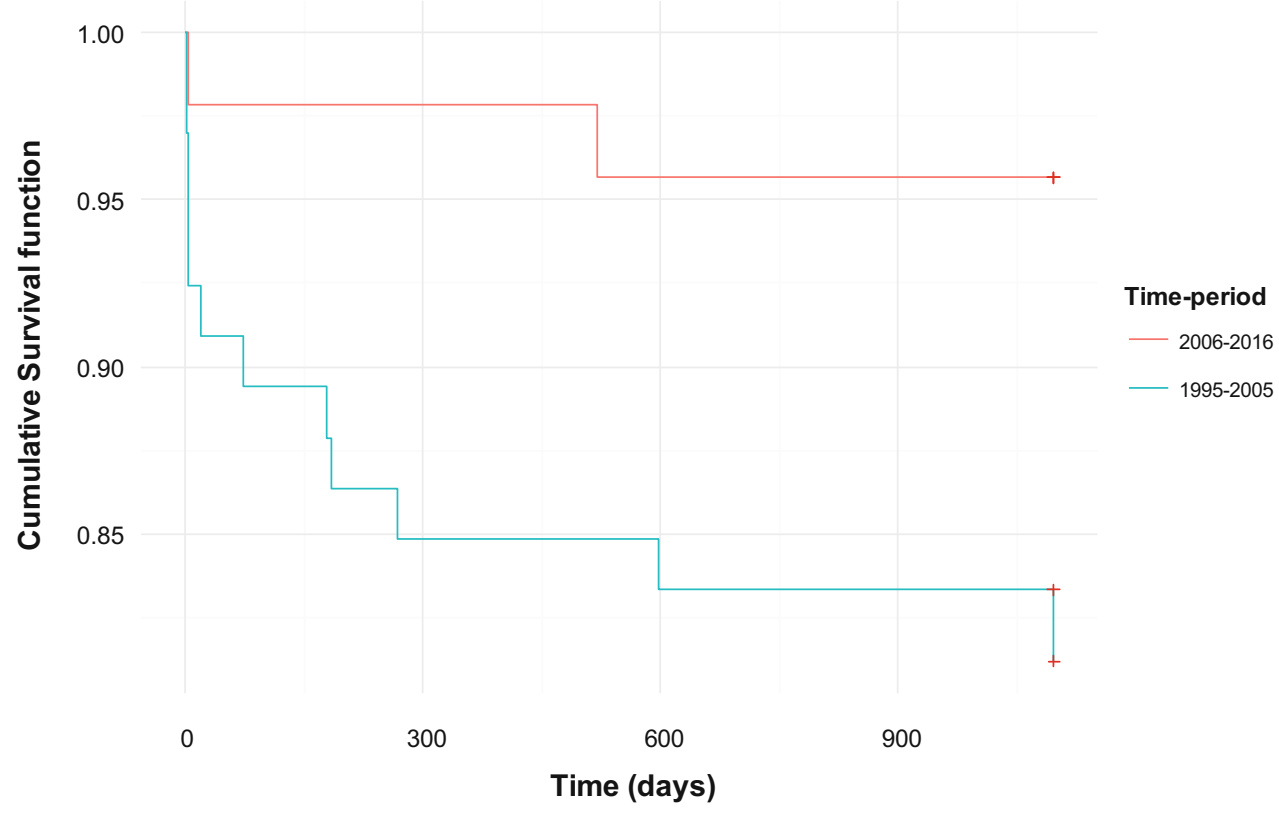

Fig. 2 Kaplan-Meier estimates of the cumulative risk of survival up to 900 days in patients with small, medium and large diaphragmatic defects

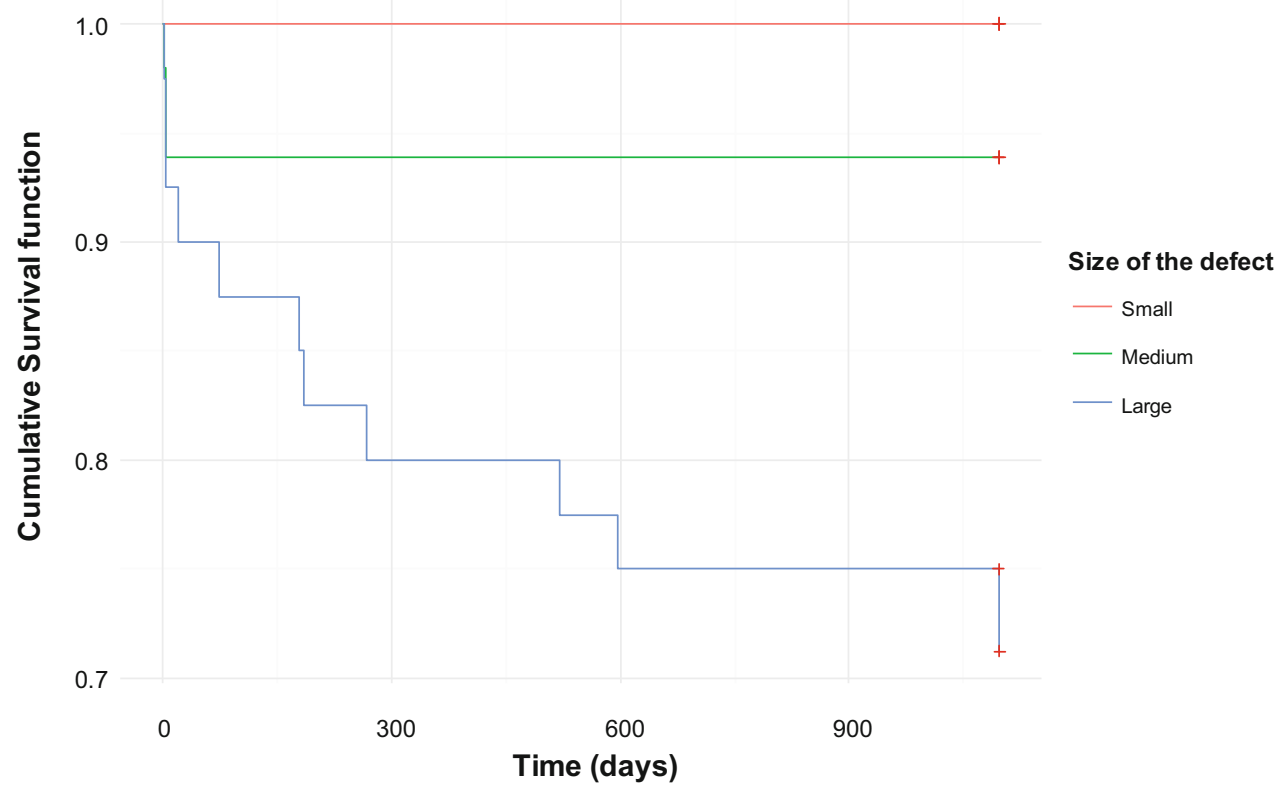

was born in the year 2000. High-frequency oscillatory ventilation and inhaled nitric oxide were increasingly used therapies during the study period. Treatments of pulmonary hypertension with sildenafil and bosentan were introduced during the late time period, 2006-2016.

In the present study, prenatal diagnosis, intrathoracic liver, low birth weight and low Apgar score were defined as independent risk factors for mortality. The mortality rate decreased significantly to $4.4 \%$ in the later time period even though there was no significant difference in the incidence of the defined risk factors, and it was lower than previously reported [1-3]. Our findings are in accordance with previous reports that found low Apgar score and low birth weight to be strong predictors of mortality [20-22]. The Congenital Diaphragmatic Hernia Study Group (CDHSG) previously published a formula utilizing birth weight and 5-min Apgar score to predict mortality in patients with $\mathrm{CDH}$ [20]. However, these factors are not specific for $\mathrm{CDH}$ and they have long been associated with adverse outcome in infants with other congenital malformations [23]. Nevertheless, avoidance of prematurity and optimizing preoperative management seem to be important to decrease the mortality in the $\mathrm{CDH}$ population. 
Table 3 Cox proportional hazards model: univariate analysis

\begin{tabular}{llll}
\hline Variable & Coefficient & $95 \%$ CI & $p$ value \\
\hline Gender & 1.57 & $(0.53-4.70)$ & 0.416 \\
Right-sided CDH & 0.93 & $(0.21-4.17)$ & 0.928 \\
Associated malformations & 2.13 & $(0.74-6.14)$ & 0.161 \\
Age at surgery & 0.95 & $(0.86-1.04)$ & 0.255 \\
Large diaphragmatic defect & 6.89 & $(1.92-24.75)$ & 0.003 \\
Birth weight per 100 g & 0.94 & $(0.88-1.00)$ & 0.034 \\
Gestational age & 0.89 & $(0.78-1.02)$ & 0.088 \\
Prenatal diagnosis & 4.32 & $(1.45-12.91)$ & 0.009 \\
Intrathoracic liver & 6.37 & $(2.00-20.33)$ & 0.002 \\
Apgar 1 min & 0.7 & $(0.55-0.90)$ & 0.004 \\
Apgar 5 min & 0.7 & $(0.55-0.89)$ & 0.004 \\
Apgar 10 min & 0.68 & $(0.52-0.88)$ & 0.003 \\
ECMO & 6.61 & $(2.06-21.13)$ & 0.001 \\
\hline
\end{tabular}

Table 4 Multivariate cox proportional hazards model: stepwise based on significant variables in univariate analyses

\begin{tabular}{llll}
\hline Variable & Coefficient & $95 \%$ CI & $p$ value \\
\hline Birth weight per 100 g & 0.93 & $(0.86-1.01)$ & 0.083 \\
Intrathoracic liver & 4.00 & $(1.15-17.20)$ & 0.03 \\
Apgar score & 0.66 & $(0.47-0.86)$ & 0.003 \\
Prenatal diagnosis & 4.55 & $(1.32-19.75)$ & 0.018 \\
\hline
\end{tabular}

The intrathoracic liver has been defined as an independent risk factor for mortality [24-28]. It is not surprising as an intrathoracic liver is indicative of a large diaphragmatic defect with early herniation of viscera resulting in severe pulmonary hypoplasia.

The frequency of associated malformations in the current study was higher in the later time period than in a meta-analysis of 102 publications from 1975 to 1998 [10]. In contrast to others, associated malformations were not defined as an independent risk factor in this study $[10,15,29,30]$.

The incidence of prenatal diagnosis was higher in the later time period (35\%) and in accordance with the pooled incidence of prenatal diagnosis in a meta-analysis of Skari et al. [10]. It was lower than in an evaluation from 2002 of prenatal diagnosis in 20 European regions with an overall prenatal detection rate of $59 \%$ in 187 cases [31]. Prenatal diagnosis was found to be the strongest predictor of mortality in our series of patients as previously reported $[10,32]$. The likelihood of prenatal detection increases with large defects with a considerable mediastinal shift and severe pulmonary hypoplasia $[10,32]$.

The CDHSG reported the defect size to be the strongest predictor of survival [4]. Although a large defect size was associated with higher mortality in the present study it was not found to be an independent risk factor for mortality.
In contrast to a meta-analysis of 2980 patients with $\mathrm{CDH}$, there was no difference in mortality between rightand left-sided $\mathrm{CDH}$ in the present study [10].

Permissive hypercapnia and "gentle ventilation" have been reported to increase survival in neonates with $\mathrm{CDH}$ $[33,34]$. A decrease in the ECMO utilization has been noted in infants managed with permissive hypercapnia and gentle ventilation strategies [33, 34]. A possible explanation for the decreased mortality in the later time period might be that the neonates with $\mathrm{CDH}$ were managed in the largest neonatal intensive care unit in the country with a wide experience in "gentle ventilation" in extremely premature neonates. Improved medical treatment of pulmonary hypertension in the later time period might also have contributed to the decreased mortality. Hagadorn et al. found that improved survival in CDH was associated with the increasing use of multiple vasodilators [35].

The benefit of ECMO in the treatment of infants with $\mathrm{CDH}$ remains unclear [36]. The efficacy of ECMO in reducing mortality has not been convincing in randomized trials $[37,38]$. The incidence of ECMO-treated patients in the present study was low, 7.5 and $6.5 \%$ in the early and later time period, respectively, and the mortality rate was $50 \%$. It was the same mortality rate as reported by the ELSO Registry in 2012 [39]. The proportion of neonates requiring ECMO has declined but the mortality rates for neonates supported on ECMO have increased [40, 41].

Our paediatric surgical centre is defined as a low-volume hospital ( $\leq 6$ cases per year) according to a previous study in 2203 infants with CDH repair [42]. They found higher mortality rates in low-volume hospitals than in highvolume hospitals ( $>10$ cases per year), 23 and 16\%, respectively. However, a more recent study in 3738 infants showed no difference in mortality between low- and highvolume hospitals [43].

The strengths of this study are the quite large number of patients and no patients were lost to follow-up. The main weakness of this study is its retrospective design and it is being representative of a single centre.

\section{Conclusion}

In the present study, mortality decreased over time, despite no significant difference in the incidence of independent risk factors and the use of ECMO between the two time periods. The mortality was lower than previously reported. The results indicate that there are many important factors involved to achieve a successful outcome after $\mathrm{CDH}$ repair. Large multicentre studies are necessary to define those critical factors and to determine optimal treatment strategies. 
Acknowledgements The authors thank all the participating children and their parents and we thank Marcus Thuresson, Statisticon AB for statistical analysis. The authors also wish to thank the HRH Crownprincess Lovisas Foundation for Scientific Research funding.

Open Access This article is distributed under the terms of the Creative Commons Attribution 4.0 International License (http://crea tivecommons.org/licenses/by/4.0/), which permits unrestricted use, distribution, and reproduction in any medium, provided you give appropriate credit to the original author(s) and the source, provide a link to the Creative Commons license, and indicate if changes were made.

\section{References}

1. Losty PD (2014) Congenital diaphragmatic hernia: where and what is the evidence? Semin Pediatr Surg 23(5):278-282

2. Coughlin MA, Werner NL, Gajarski R, Gadepalli S, Hirschl R, Barks J et al (2016) Prenatally diagnosed severe CDH: mortality and morbidity remain high. J Pediatr Surg 51(7):1091-1095

3. Benachi A, Cordier A-G, Cannie M, Jani J (2014) Advances in prenatal diagnosis of congenital diaphragmatic hernia. Semin Fetal Neonatal Med. 19(6):331-337

4. Congenital Diaphragmatic Hernia Study Group, Lally KP, Lally PA, Lasky RE, Tibboel D, Jaksic T et al (2007) Defect size determines survival in infants with congenital diaphragmatic hernia. Pediatrics 120(3):e651-e657

5. Lally KP, Lasky RE, Lally PA, Bagolan P, Davis CF, Frenckner BP, Hirschl RM, Langham MR, Buchmiller TL, Usui N, Tibboel D, Wilson JM, Congenital Diaphragmatic Hernia Study Group (2013) Standardized reporting for congenital diaphragmatic hernia - an international consensus. J Pediatr Surg. 48(12):2408-2415

6. Antonoff MB, Hustead VA, Groth SS, Schmeling DJ (2011) Protocolized management of infants with congenital diaphragmatic hernia: effect on survival. J Pediatr Surg 46(1):39-46

7. Wynn J, Krishnan U, Aspelund G, Zhang Y, Duong J, Stolar CJH et al (2013) Outcomes of congenital diaphragmatic hernia in the modern era of management. J Pediatr. 163(1):114-119

8. Tracy ET, Mears SE, Smith PB, Danko ME, Diesen DL, Fisher KA et al (2010) Protocolized approach to the management of congenital diaphragmatic hernia: benefits of reducing variability in care. J Pediatr Surg 45(6):1343-1348

9. Danzer E, Hedrick HL (2014) Controversies in the management of severe congenital diaphragmatic hernia. Semin Fetal Neonatal Med. 19(6):376-384

10. Skari H, Bjornland K, Haugen G, Egeland T, Emblem R (2009) Congenital diaphragmatic hernia: a meta-analysis of mortality factors. J Pediatr Surg 35(8):1187-1197

11. Levison J, Halliday R, Holland AJA, Walker K, Williams G, Shi E et al (2006) A population-based study of congenital diaphragmatic hernia outcome in New South Wales and the Australian Capital Territory, Australia, 1992-2001. J Pediatr Surg 41(6):1049-1053

12. Schaible T, Kohl T, Reinshagen K, Brade J, Neff KW, Stressig R et al (2012) Right- versus left-sided congenital diaphragmatic hernia: postnatal outcome at a specialized tertiary care center. Pediatr Crit Care Med J Soc Crit Care Med World Fed Pediatr Intensive Crit Care Soc. 13(1):66-71

13. Harting MT, Lally KP (2014) The Congenital Diaphragmatic Hernia Study Group registry update. Semin Fetal Neonatal Med 19(6):370-375

14. Grethel EJ, Farrell J, Ball R, Lee H, Nobuhara KK (2007) Congenital diaphragmatic hernia associated with spinal anomalies. Obstet Gynecol. 109(2 Pt2):485-488
15. Bollmann R, Kalache K, Mau H, Chaoui R, Tennstedt C (1995) Associated malformations and chromosomal defects in congenital diaphragmatic hernia. Fetal Diagn Ther 10(1):52-59

16. Boloker J, Bateman DA, Wung JT, Stolar CJ (2002) Congenital diaphragmatic hernia in 120 infants treated consecutively with permissive hypercapnea/spontaneous respiration/elective repair. J Pediatr Surg 37(3):357-366

17. Wung JT, Sahni R, Moffitt ST, Lipsitz E, Stolar CJ (1995) Congenital diaphragmatic hernia: survival treated with very delayed surgery, spontaneous respiration, and no chest tube. J Pediatr Surg 30(3):406-409

18. Hollinger LE, Lally PA, Tsao K, Wray CJ, Lally KP, Congenital Diaphragmatic Hernia Study Group (2014) A risk-stratified analysis of delayed congenital diaphragmatic hernia repair: does timing of operation matter? Surgery. 156(2):475-482

19. Spitz L, Kiely EM, Morecroft JA, Drake DP (1994) Oesophageal atresia: at-risk groups for the 1990s. J Pediatr Surg 29:723-725

20. Congenital Diaphragmatic Hernia Study Group (2001) Estimating disease severity of congenital diaphragmatic hernia in the first 5 minutes of life. J Pediatr Surg 36(1):141-145

21. Levison J, Halliday R, Holland AJA, Walker K, Williams G, Shi E et al (2006) A population-based study of congenital diaphragmatic hernia outcome in New South Wales and the Australian Capital Territory, Australia, 1992-2001. J Pediatr Surg 6:1049-1053

22. Heiss KF, Clark RH (1995) Prediction of mortality in neonates with congenital diaphragmatic hernia treated with extracorporeal membrane oxygenation. Crit Care Med 23(11):1915-1919

23. Waterston DJ, Carter RE, Aberdeen E (1962) Oesophageal atresia: tracheo-oesophageal fistula. A study of survival in 218 infants. Lancet 1:819-822

24. Mullassery D, Ba'ath ME, Jesudason EC, Losty PD (2010) Value of liver herniation in prediction of outcome in fetal congenital diaphragmatic hernia: a systematic review and meta-analysis. Ultrasound Obstet Gynecol Off J Int Soc Ultrasound Obstet Gynecol. 35(5):609-614

25. Hedrick HL, Danzer E, Merchant A, Bebbington MW, Zhao H, Flake AW et al (2007) Liver position and lung-to-head ratio for prediction of extracorporeal membrane oxygenation and survival in isolated left congenital diaphragmatic hernia. Am J Obstet Gynecol. 197(4):422.e1-422.e4

26. Casaccia G, Ravà L, Bagolan P, di Ciommo VM (2008) Predictors and statistical models in congenital diaphragmatic hernia. Pediatr Surg Int 24(4):411-414

27. Harrison MR, Mychaliska GB, Albanese CT, Jennings RW, Farrell JA, Hawgood S et al (1998) Correction of congenital diaphragmatic hernia in utero IX: fetuses with poor prognosis (liver herniation and low lung-to-head ratio) can be saved by fetoscopic temporary tracheal occlusion. J Pediatr Surg. 33(7):1017-1023

28. Kitano $Y$, Nakagawa S, Kuroda T, Honna T, Itoh Y, Nakamura T et al (2005) Liver position in fetal congenital diaphragmatic hernia retains a prognostic value in the era of lung-protective strategy. J Pediatr Surg 40(12):1827-1832

29. Grethel EJ, Farrell J, Ball R, Lee H, Nobuhara KK (2007) Congenital diaphragmatic hernia associated with spinal anomalies. Obstet Gynecol 109(2 Pt2):485-488

30. American Academy of Pediatrics Section on Surgery, American Academy of Pediatrics Committee on Fetus and Newborn, Lally KP, Engle W (2008) Postdischarge follow-up of infants with congenital diaphragmatic hernia. Pediatrics 121(3):627-632

31. Garne E, Haeusler M, Barisic I, Gjergja R, Stoll C, Clementi M et al (2002) Congenital diaphragmatic hernia: evaluation of prenatal diagnosis in 20 European regions. Ultrasound Obstet Gynecol Off J Int Soc Ultrasound Obstet Gynecol. 19(4):329-333 
32. Gallot D, Coste K, Francannet C, Laurichesse H, Boda C, Ughetto $S$ et al (2006) Antenatal detection and impact on outcome of congenital diaphragmatic hernia: a 12-year experience in Auvergne, France. Eur J Obstet Gynecol Reprod Biol. 125(2):202-205

33. Guidry CA, Hranjec T, Rodgers BM, Kane B, McGahren ED (2012) Permissive hypercapnia in the management of congenital diaphragmatic hernia: our institutional experience. J Am Coll Surg 214(4):640-645

34. Lupo E, Castoldi F, Maestri L, Rustico M, Dani C, Lista G (2013) Outcome of congenital diaphragmatic hernia: analysis of implicated factors. Minerva Pediatr 65(3):279-285

35. Hagadorn JI, Brownell EA, Herbst KW, Trzaski JM, Neff S, Campbell BT (2015) Trends in treatment and in-hospital mortality for neonates with congenital diaphragmatic hernia. J Perinatol 35(9):748-754

36. Snoek KG, Reiss IK, Greenough A, Capolupo I, Urlesberger B, Wessel L, Storme L, Deprest J, Schaible T, van Heijst A, Tibboel D, CDH EURO Consortium (2016) Standardized Postnatal Management of Infants with Congenital Diaphragmatic Hernia in Europe: The CDH EURO Consortium Consensus-2015 Update. Neonatology. 110(1):66-74

37. Mugford M, Elbourne D, Field D (2008) Extracorporeal membrane oxygenation for severe respiratory failure in newborn infants. Cochrane Database Syst Rev 16(3):CD001340
38. Snoek KG, Capolupo I, van Rosmalen J, Hout Lde J, Vijfhuize S, Greenough A, Wijnen RM, Tibboel D, Reiss IK, CDH EURO Consortium (2016) Conventional mechanical ventilation versus high-frequency oscillatory ventilation for congenital diaphragmatic hernia: a randomized clinical trial (The VICI-trial). Ann Surg. 263(5):867-874

39. Paden ML, Conrad SA, Rycus PT, Thiagarajan RR, ELSO Registry (2013) Extracorporeal Life Support Organization Registry Report 2012. ASAIO J. 59(3):202-210

40. Paden ML, Rycus PT, Thiagarajan RR (2014) Update and outcomes in extra-corporeal life support. Semin Perinatol 38(2):65-70

41. Mok YH, Lee JH, Cheifetz IM (2016) Neonatal extracorporeal membrane oxygenation: update on management strategies and long-term outcomes. Adv Neonatal Care. 16(1):26-36

42. Bucher BT, Guth RM, Saito JM, Najaf T, Warner BW (2010) Impact of hospital volume in-hospital mortality of infants undergoing repair of congenital diaphragmatic hernia. Ann Surg 252(4):635-642

43. Kane JM, Harbert J, Hohmann S, Pillai S, Behal R, Selip D, Johnson T (2015) Case volume and outcomes of congenital diaphragmatic hernia surgery in academic medical centers. Am J Perinatol 32(9):845-852 